iii. Sample tracking form

e. Self-Study Visits (resources to be developed at a later phase of this project)

2. STFM will explore the development of a mobile app to track patient encounters/procedures

3. STFM will address faculty development needs through STFM conferences and On the Road presentations

Plans are to launch the accreditation toolkit, with the exception of online modules, online forms, and mobile applications by July 30, 2014. Faculty development modules and training will follow.

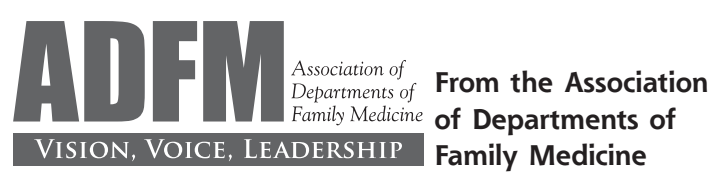

Ann Fam Med 2013;581-582. doi:10.1370/afm.1588.

\section{ANOTHER CENTURY OF "REFORM WITHOUT CHANGE?"}

"And the seasons, they go round and round And the painted ponies go up and down We're captive on a carousel of time"

(Joni Mitchell 1970)

The 1910 Flexner report is credited with beginning the modern era of medical education. ${ }^{.}$Since that time, a regular calliope of calls for changes in the way that medical students are selected and educated has been heard. Yet authors such as Bloom ${ }^{2,3}$ and Christakis ${ }^{4}$ have noted that these calls for reform are 'remarkably consistent,' with perennial themes and similar recommendations. Whitehead ${ }^{5}$ likens this revolving pattern to a carousel, observing that "medical educators were regularly returning with fresh and un-remembering minds, to the same concerns."

What are the reasons that the same "ponies go up and down $n_{i}$ and is the current wave of curricular reforms likely to yield any different results? Will proposed reforms overcome the resistance to fundamental change that has so far stymied the reformers' stated desires to achieve a system of medical education to better serve the needs of the public? One source of resistance to real change was pointedly cited by Bloom: "The scientific mission of academic medicine has crowded out its social responsibility to train for society's most basic health-care delivery needs."

Comprehensive reviews of curricular reform by Christakis $^{4}$ and Whitehead ${ }^{5}$ found similar conclu- sions, emphasizing the need for increased generalist training and concerns about overspecialization. In the 1990s, curricular reform efforts funded by the Health Resources Services Administration and private foundations enthusiastically initiated novel curricular changes. Academic institutions watched a transient increase in medical student selection of generalist disciplines. The failure of a concurrent systemic reimbursement reform contributed to another decline in student interest in primary care. ${ }^{6}$

New reports promote novel efforts to reshape the health care workforce for the 21st century. ${ }^{7,8}$ Coupled with a parallel wave of curricular revision, what factors offer hope that academic institutions will go beyond focus on the oft-recommended goals of selecting the right medical students, providing a more suitable curriculum through more suitable methods, and encouraging a professional identity that is immune to the hidden curriculum? This hidden curriculum, including what Funkenstein" called "the ideology of the era," has obstructed the most idealistic of curriculum planners' intent to influence students' perception of generalism and the relevance of population needs to their particular specialty choice.

What is required to hold academic medical centers accountable for preparing a workforce capable of improving population health? How much of the hidden curriculum and influential "ideology of the era" can academic medical centers control?

Surveys suggest that most $(53 \%$ in 2011 and $65 \%$ in 2012) chairs of academic departments of family medicine are being asked to lead health care delivery innovations. Family medicine educators across the country are emphasizing patient-focused team-based learning, incorporating cost/value issues and practicebased quality improvement projects into medical student experiences. Departments of family medicine are leading unique public health initiatives and demonstrating the value of primary care physicians' role in improving the health of the public. Is this enough? Or will academic institutions continue to "impute novelty" to curricular issues and continue to avoid examining factors linking resistance to change with the continued struggle to prepare a health care workforce best suited to address the health needs of our citizens?

The opinions are those of the authors. They do not represent official policy of the Department of Defense, the Department of the Navy or the Uniformed Services University.

Christine Matson, Ardis Davis, Mark Stephens, and the ADFM Education Transformation Committee

\section{References}

1. Flexner, A. Medical Education in the United States and Canada. New York, NY.: Carnegie Foundation; 1910. 
2. Bloom SW. Structure and ideology in medical education: an analysis of resistance to change. J Health Soc Behav. 1988;29(4):294-306.

3. Bloom SW. The medical school as a social organization: the sources of resistance to change. Med Educ. 1989;23(3):228-241.

4. Christakis NA. The similarity and frequency of proposals to reform US medical education. Constant concerns. JAMA. 1995;274(9):706-711.

5. Whitehead CR, Hodges BD, Austin Z. Captive on a carousel: discourses of "new" in medical education 1910-2010. Adv Health Sci Educ Theory Pract. 2013;18(4):755-768.

6. Ebell MH. Future salary and US residency fill rate revisited. JAMA. 2008;300(10):1131-1132.

7. Frenk J, Chen L, Bhutta ZA, et al. Health professionals for a new century: transforming education to strengthen health systems in an interdependent world. Lancet. 2010;376(9756):1923-1958.

8. American Medical Association (AMA). Accelerating change in medical education. 2012. http://www.ama-assn.org/ama/pub/about-ama/ strategic-focus/accelerating-change-in-medical-education.page.

9. Funkenstein DH. Some myths about medical school admissions. J Med Educ. 1955;30(2):81-88.

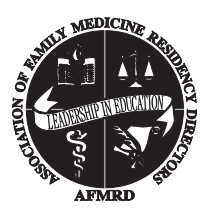

From the Association of Family Medicine Residency Directors

Ann Fam Med 2013;582. doi:10.1370/afm.1589.

\section{FM-RC REQUIREMENTS - LESS IS MORE}

The ACGME Review Committee of Family Medicine (RC-FM) released its revision of the core requirements earlier this year for the first time since 2007. The proposed requirements, at 31 pages, are $20 \%$ shorter than the earlier requirements. The new requirements, rather than detailing the specifics needed for each and every aspect of family medicine education, direct programs as to what is most important, they provide the "spirit of the law," but have eliminated much of the "letter." For example, the old $\mathrm{RC}$ requirements for a family medicine center (FMC) were 3 pages long; the new guidelines for a family medicine practice (FMP) are one page, and much more general than specific.

There are 2 important benefits to the above changes, and 2 notes of caution. The first benefit is the new requirements addresses the reductionist view of human health as the sum of the individual parts that developed in our requirements. Family medicine as a specialty specializes in people ; it is the only specialty not limited by age, gender, or organ system. To define the knowledge needed by family physicians as a litany of systems of the human body undermines the quintessential nature of our specialty.

The second important benefit of the proposed changes is that they allow for more autonomy of pro- grams to address how to best teach family medicine. As a specialty, we struggle to balance the common essence of what it means to be a family physician with different geographical needs. The proposed requirements give an overview of what is needed, without descending into a laundry list of specifics. It allows the program director to modify the curriculum of the program to best meet the clinical and educational needs of his or her own program, and of the community they serve.

The notes of caution relate to how we as program directors interact with new requirements. First, the $\mathrm{RC}$-FM is to be commended for reducing our new proposed program requirements from 39 to 31 pages. One of the contributing factors for the requirements being so long in the first place was the interaction between program directors asking for clarification on citations, and a well-intentioned review committee providing it - and we slowly increased the length and specificity of our program requirements. The specifics become a double-edged sword-greater clarity in requirements means greater detail, which means longer and more cumbersome requirements that can stifle innovation and creativity, and interfere with a program flexing to meet the needs of its community.

The second caution is a need to shift our source for justification of institutional resources away from the pared down $\mathrm{RC}$ requirements, and towards the readily updatable RC family Medicine FAQ document. This will allow programs to still utilize the ACGME as an official backstop without bloating the requirements again.

AFMRD is well positioned as an organization to help our members meet the challenges and seize the opportunities of these changes. Two recent initiatives undertaken by AFMRD to help family medicine programs be the best they can be: The Family Medicine Residency Curriculum Resource (RCR) and the Residency Performance Index (RPI). The RCR will allow curriculum to be shared among programs nationwide. The Residency Performance Index (RPI) allows programs to self-assess, compare themselves to their peers, and develop improvement strategies. We also recognize there is much work to be done in the areas of innovation support and measurement and communication. There are many programs of excellence among us, trying many innovations, led by directors of excellence and creativity, and the more AFMRD can support all of them, allow them to exchange ideas and learn from each other, the better off we will all be.

Stephen Scbultz, MD, Natasba Bbuyan, $M D_{i}$

Brian Crownover, $M D_{i}$ Grant Hoekzema, $M D_{i}$

Lisa Maxwell, MDi Michael Mazzone, $M D_{i}$

W. Fred Miser, $M D_{i}$ Karen Mitchell, MDi

Todd Shaffer, MD, MBA, Michael Tuggy, MD 